\title{
Preliminary Report on the Results of Statistical and Ichthyological Investigations made at the Plymouth Laboratory.
}

By

Georg Duncker, Ph.D.

DURING my stay, from August to October, 1897, at the Laboratory of the Marine Biological Association of the United Kingdom, I was especially engaged in investigating the variability of Pleuronectes flesus, Linn., and Siphonostoma typhle, Linn. Of the results so obtained, some of more local faunistic importance are briefly reported here.

I take this opportunity of expressing my hearty thanks to the officers of the Laboratory, especially to the Director, Mr. E. J. Allen, for their help and kind interest in my researches. A paper containing a full statement of the statistical results has been prepared, and will be published shortly.

\section{Pleuronectes flesus, Linn.}

The flounders of Plymouth, when compared with those of the Baltic and the south-eastern parts of the North Sea, form a distinct race. The characteristics of this race are:

1. A high number of fin-rays in the dorsal and anal fin (average, dorsal 61-62, anal 43-44).

2. Almost entirely smooth squamation on the blind side. In both respects it is similar to the variety Pleuronectes italicus, Günther, of the Mediterranean.

The variation in the number of fin-rays has been studied in 1120 individuals, of which $602(=53.75$ per cent.) were males, and 518 $(=46.25$ per cent.) were females. Of the males $40(=6.6$ per cent.) had the eyes on the left side of the head, of the females only 20 ( $=3.8$ per cent.). On drawing the curves representing the observed total lengths for each sex separately, a distinct size group, similar to 
those suggested by Petersen,* was found only for the small individuals from 7 to $14 \mathrm{~cm}$. In other portions of the curve no distinct humps were observed.

The males proved more variable than the females in the number of fin-rays. Table I. gives the indices of variability (Airy's error of mean square $\sqrt{\left.\frac{\overline{\Sigma\left(x^{2}\right)}}{n}\right)}$ for each fin in both male and female.

TABLE I., showing the Indices of variability of the number of fin-rays.

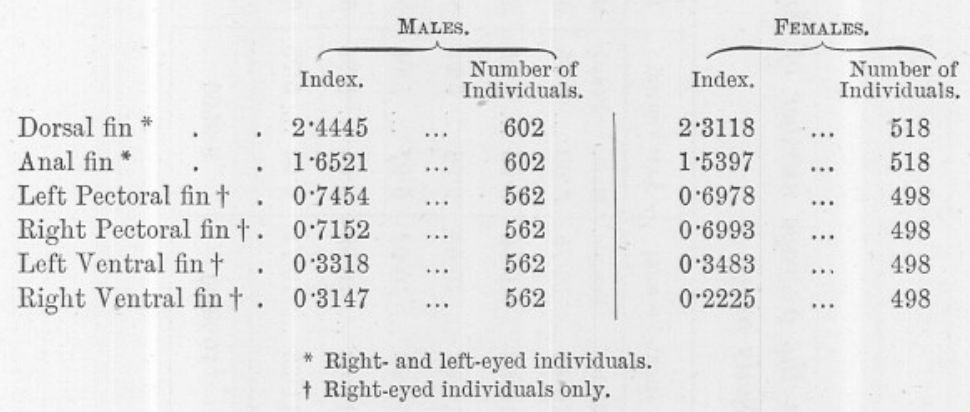

Differences of age or sex corresponding to differences in the number of fin-rays were not distinctly shown in the dorsal, anal, and ventral fins. In both pectoral fins a slight increase of the numbers of rays seems to occur with age (i.e. with increase of total length).

Table II. gives the arithmetical mean values of the number of finrays in six size groups of both sexes. Group I. contains individuals below $10 \mathrm{~cm}$. in total length; group II., from 10 to $14.9 \mathrm{~cm}$., etc.; group VI., above $30 \mathrm{~cm}$. (See page 174.)

The variation is normal in three cases; in three (dorsal and both ventral fins) it is skew, according to Pearson's Type IV. (Phil. Trans. Roy. Soc., Vol. 186 A.); in the dorsal, however, this skewness is only slight. The correlation (according to Pearson'st formula) between the numbers of fin-rays of the dorsal and anal fin is very high, $r=0.672 . \neq$ This is higher even than that of the pectoral fins, $r=0.588$. The latter I find to be less than in the symmetrical species mentioned below, in which $\mathrm{r}=0.700$ and 0.720 respectively. The correlation of the ventral fins is only $0 \cdot 2085$.

* Report of the Danish Biol. Station, IV., 1893, "The Biology of our Flatfishes."

† Phil. Trans. Roy. Soc., Vol. 187 A, p. 265.

\# Compare this with the corresponding values of the Acanthopterygians Acerina cernua, Linn., $\mathrm{r}=0.238$, and Cottus gobio, Linn., $\mathrm{r}=0.300$. 
TABLE II., showing the size-differences in the average number of fin-rays (right-eyed individuals only).

\begin{tabular}{|c|c|c|c|c|c|c|c|c|}
\hline \multirow[b]{2}{*}{$\begin{array}{l}\text { SIZE. } \\
\text { I. }\end{array}$} & \multirow[b]{2}{*}{. } & Dorsal Fin. & Anal Fin. & Left Pectoral. & Right Pectoral & Left Ventral. & Right Ventral. & $\begin{array}{l}\text { Number of } \\
\text { Individuals. }\end{array}$ \\
\hline & & 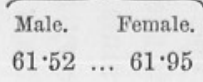 & $\begin{array}{crr}\text { Male. } & \text { Female. } \\
43 \cdot 80 & \ldots & 43 \cdot 75\end{array}$ & $\begin{array}{ccc}\text { Male. } & \text { Female } \\
9.96 & \ldots & 10.05\end{array}$ & 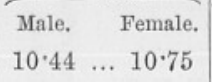 & $\begin{array}{l}\text { Male. } \\
6.00 \quad \ldots \quad 5.75\end{array}$ & $\begin{array}{ccc}\text { Male. } & \text { Female. } \\
6.00 & \ldots & 6.05\end{array}$ & $\begin{array}{cc}\text { Male. } & \text { Female. } \\
25 \quad \ldots & 20\end{array}$ \\
\hline II. & . & $61 \cdot 27 \quad \ldots \quad 61 \cdot 25$ & $43 \cdot 68 \ldots .43 \cdot 28$ & $9 \cdot 86 \quad \ldots \quad 9 \cdot 74$ & $10 \cdot 60 \ldots 10.56$ & $5 \cdot 96 \quad \ldots .5 \cdot 95$ & $6 \cdot 01 \ldots .5 \cdot 99$ & $113 \ldots 115$ \\
\hline III. & . & $61 \cdot 74 \ldots 61 \cdot 91$ & $43.84 \ldots 43 \cdot 56$ & $10.22 \ldots 10.02$ & $10.88 \ldots 10.63$ & $5 \cdot 93 \quad \ldots .5 \cdot 96$ & $5 \cdot 95 \quad . . \quad 5 \cdot 95$ & $148 \ldots 116$ \\
\hline IV. & . & $61 \cdot 76 \quad \ldots \quad 62 \cdot 11$ & $43 \cdot 46 \quad \ldots \quad 44 \cdot 03$ & $10 \cdot 26 \quad \ldots \quad 10 \cdot 31$ & $10.93 \quad \ldots \quad 10.93$ & $5 \cdot 97 \ldots .5 \cdot 95$ & $5 \cdot 99 \ldots 5 \cdot 96$ & $170 \quad \ldots \quad 127$ \\
\hline V. & . & $61 \cdot 59 \ldots 61 \cdot 72$ & $43.43 \ldots .43 \cdot 78$ & $10.34 \ldots 10.40$ & $11.03 \ldots 10.93$ & $5 \cdot 94 \ldots .5 \cdot 95$ & $5.93 \quad \ldots .5 .98$ & $100 \ldots 82$ \\
\hline VI. & . & $62 \cdot 17 \ldots 61 \cdot 95$ & $43 \cdot 50 \ldots 43 \cdot 87$ & $10.00 \ldots 10.29$ & $11 \cdot 33 \ldots 10 \cdot 71$ & $6.00 \ldots 5.95$ & $6.00 \ldots 6.00$ & $6 \ldots \quad 38$ \\
\hline Tot & average) & $61 \cdot 7214$ & $43 \cdot 6098$ & $10 \cdot 1425$ & $10 \cdot 8036$ & $5 \cdot 9500$ & $5 \cdot 9745$ & 1060 \\
\hline
\end{tabular}




\section{Syngnathus rostellatus, Nilss.}

The reasons for separating this common and widely-distributed species from $S$. acus, Linn., are the following:-

1. The differences between the two forms are so distinct and of such a degree that they are not likely to be due to differences of age.

A comparison between twenty-two individuals of the former species and forty-seven of the latter, gives the following ranges of variation :-

\begin{tabular}{|c|c|c|c|c|c|}
\hline & & \multicolumn{3}{|c|}{ S. rostellatus, Nilss. } & S. acus. \\
\hline Ann. corp. & . & 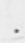 & . 13-15 & $\ldots$ & $19-20-$ \\
\hline Ann. caud. & . & & . $\quad 39-41$ & $\ldots$ & $43-46$ \\
\hline Summa ann. & . & . & . $52-56$ & $\ldots$ & $62-66$ \\
\hline Ann. p. dors. & . & . & . $10-12$ & $\ldots$ & $8-11$ \\
\hline Rad. p. dors. & . & . & . $36-44$ & $\ldots$ & $36-45$ \\
\hline Ann. burs. gen & & & . $20-25$ & $\ldots$ & $25-28$ \\
\hline Observed Tota & l Length & . & . $7 \cdot 7-16.4 \mathrm{~cm}$. & $\ldots$ & $16 \cdot 0-44 \cdot 8 \mathrm{~cm}$. \\
\hline
\end{tabular}

2. The individual variation in the number of body rings in the Syngnathidae (corresponding to the individual variation of abdominal vertebræ in other fishes) is a very low one. (Siphonostoma typhle, Linn. Syngnathus pelagicus.)

3 . The fully-developed young in the brood-pouches of the males of both forms differ by the same number of rings as the adult, as well as differing in their total lengths. (They are about $1.5 \mathrm{~cm}$. and $2.5 \mathrm{~cm}$. respectively.)

4. Sexual maturity has been observed in individuals of S. rostellatus, Nilss., above $11 \mathrm{~cm}$. long, in $S$. acus not below $30 \mathrm{~cm}$.

5. Cross-breeding between the two forms seems unlikely, in consequence of the difference of the sizes of the eggs and brood-pouches in the two cases.

At Plymouth I obtained S. rostellatus, Nilss., from Cawsand Bay and from the Yealm River; S. acus from the same places and from the Hamoaze. I also possess specimens of S. rostellatus, Nilss., from the western Baltic, the North Sea, and the Mediterranean. Through the kindness of Mr. E. W. L. Holt I was also able to compare some specimens from the River Humber. 